\title{
Physicians will happily adopt information technology
}

\section{David Zitner}

$\infty$

See related article page 1573

I $\mathrm{n}$ this issue, Lapointe and Rivard ${ }^{1}$ report on their analysis of computer information system (CIS) implementations at 3 hospitals to understand better the dynamics of physicians' resistance to such implementations. The level of resistance varied. In 2 cases it was met with responses from implementers that reinforced the resistance behaviours, and the systems were eventually removed; in the other case the responses to the resistance were supportive, the resistance decreased and the system was ultimately successful.

Lapointe and Rivard suggest that an understanding of power dynamics is critical to learn why modern health information tools and techniques are not readily adopted. The slow adoption of health information systems in Canada is startling because Canada is thought of as a civilized country that often undertakes collective action around shared interests. Although an understanding of power and the relationships between various constituencies is important in a civilized society, theories of power and how power is exercised are not critical to learn why most Canadian physicians fail to adopt modern health information tools.

The well-accepted concepts in economics and psychology of incentive and reward are more than sufficient to explain many of the peculiarities of health care in Canada, including our health care system's failure to undertake actions that we all agree will benefit patients. Today's failures are easily explained by concepts developed in 1776 by the economist Adam Smith in his book The Wealth of Nations:

Whoever offers to another a bargain of any kind, proposes to do this. Give me that which I want, and you shall have this which you want, is the meaning of every such offer; and it is in this manner that we obtain from one another the far greater part of those good offices which we stand in need of. It is not from the benevolence of the butcher, the brewer, or the baker, that we expect our dinner, but from their regard to their own interest. We address ourselves, not to their humanity but to their self-love, and never talk to them of our own necessities but of their advantages.

Even Adam Smith recognized that financial rewards are not the only rewards. Often, especially for the caring professions, financial rewards are less important than work satisfaction. Thoughtful administrators must consider professional and financial rewards whenever they contemplate new initiatives.

Canadian physicians have heavy caseloads and little time, and many believe they must comply with inappropriate bureaucratic rules that reduce their ability to provide effective and efficient care. The perception and reality "so much to do, so little time" leads to reduced professional satisfaction. Professional satisfaction is also reduced when physicians observe harms to patients who have to wait so long for necessary care. Physicians who spend more time recording information, in either a paper or electronic health record, have less time for patient care and often experience economic and professional repercussions. ${ }^{2}$

In each of the 3 cases examined by Lapointe and Rivard, use of the CIS meant that clinicians would need to take more time to care for a patient during a particular encounter. That the doctors felt "forced" to use the tools imposed by the hospital is not necessarily the problem. The real problem is that the tools reduced the physicians' ability to provide timely care. Usually, people who are "forced" to do things that benefit themselves do not complain. A boss who insists on a process that dramatically reduces the time to complete a job, without an effect on job satisfaction or financial compensation, is unlikely to meet resistance. On the other hand, a boss who insists that an employee do something that is not in his or her own best interests will be more likely to generate resistance.

Virtually every clinical specialty, given the opportunity, has rapidly adopted the use of a picture archiving communication system (PACS) for diagnostic imaging. PACS improves the efficiency of care because clinicians can easily retrieve and read diagnostic images, including radiographs, from anywhere in the world. There was no resistance to the implementation of the system because PACS works!

If hospitals experience resistance from clinicians after a CIS implementation, they would be wise to explore the reasons for resistance and develop strategies for success. These strategies include learning what the various stakeholders (clinicians, administrators, payers and patients) expect to gain and how the system will enhance or impair work flow. Clinicians would be less resistant if creative solutions were adopted to deal with data-entry issues. For example, giving clinicians the opportunity to dictate notes and orders and having someone else transcribe them into the system would increase efficiency and cooperation. ${ }^{3}$

Had the 2 hospitals in Lapointe and Rivard's study that encountered resistance and eventually withdrew the systems explored the reasons for failure, the implementations might have succeeded. The structure for implementation and analysis of new information technology must include experts who represent at least the most important stakeholder groups, including clinicians, administrators, payers and patients. Formal usability testing of the software using validated methods must be part of evaluations done before and after an implementation. Without such formal testing, any claims that imply that a failure to adopt the technology is due to the clinicians' state of mind as "mischievous resisters" or to a "power struggle" avoids the most important issues related to the use- 
fulness of the software and represents an inappropriate form of prejudice. Proper usability testing, designed with stakeholder representation, ensures that clinicians, administrators and patients will not be surprised by the failure to adopt dysfunctional information technology.

Physicians are enthusiastic adopters of new technologies, including PACS, video cameras and BlackBerries. They are equally likely to adopt, enthusiastically and happily, information technology solutions that improve their own lives and the lives of their patients.

This article has been peer reviewed.

David Zitner is the Director of Medical Informatics at Dalhousie University, Halifax, NS.
Competing interests: None declared.

\section{REFERENCES}

I. Lapointe L, Rivard S. Getting physicians to accept new information technology: insights from case studies. CMAJ 2006;I74(II):1573-8.

2. Poissant L, Pereira J, Tamblyn R, et al. The impact of electronic health records on time efficiency of physicians and nurses: a systematic review. J Am Med Inform Assoc 2005; (I2):505-I6.

3. Walsh SH. The clinician's perspective on electronic health records and how they can affect patient care. BMJ 2004;328:1184-7.

Correspondence to: Dr. David Zitner, Director, Medical Informatics, Dalhousie University Medical School, Rm. CII5, 5849 University Ave., Halifax $\mathrm{NS}_{3} \mathrm{H}_{4} \mathrm{H}_{7}$; fax 902 494-I642; david.zitner@dal.ca

\section{How you can get involved in the CMA!}

The CMA is committed to providing leadership for physicians and promoting the highest standard of health and health care for Canadians. To strengthen the Association and be truly representative of all Canadian physicians, the CMA needs to hear from members interested in serving in elected positions and on appointed committees and advisory groups.

The CMA structure comprises both governing bodies and advisory bodies either elected by General Council or appointed by the CMA Board of Directors. The Board of Directors - elected by General Council - has divisional, affiliate, resident and student representation, is responsible for the overall operation of the CMA and reports to General Council on issues of governance. CMA councils and committees advise the Board of Directors and make recommendations on specific issues of concern to physicians and the public. Five core councils and committees consist of either divisional or regional representation, while other statutory and special committees, and task forces consist of individuals with interest and expertise in subject-specific fields. Positions on one or more of these committees may become available in the coming year.

For further information on how you can get involved, please contact:

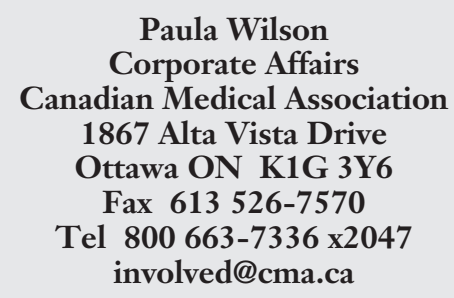

By getting involved, you will have an opportunity to make a difference.

We hope to hear from you! 